\title{
Improvement of Sliding Performance for Ball on Disc Tribo-Partners Using Graphite Like Carbon Solid Lubricant Coating
}

\author{
Xiaobin Wen' ${ }^{1}$, Huantao Yaoㄹ, Shicai Yang2* \\ ${ }^{1}$ Kingmag Precise Sci-TeCh Ltd., Fuming Industrial Estate, Dongguan, China \\ ${ }^{2}$ Miba Coating Group, Teer Coatings Ltd., West Stone House, West Stone, Berry-Hill-Industrial-Estate, Droitwich, \\ Worcestershire, UK \\ Email: xiaobin.wen@kingmagcoatings.cn, *shicai.yang@miba.com
}

How to cite this paper: Wen, X.B., Yao, H.T. and Yang, S.C. (2018) Improvement of Sliding Performance for Ball on Disc TriboPartners Using Graphite Like Carbon Solid Lubricant Coating. Materials Sciences and Applications, 9, 191-209.

https://doi.org/10.4236/msa.2018.91013

Received: October 26, 2017

Accepted: January 26, 2018

Published: January 29, 2018

Copyright $\odot 2018$ by authors and Scientific Research Publishing Inc. This work is licensed under the Creative Commons Attribution International License (CC BY 4.0).

http://creativecommons.org/licenses/by/4.0/

\begin{abstract}
Sliding wear tests of chilled cast iron tappet-disc and cam-ball tribo-partners were conducted by using ball on disc testing device. Magnetron sputtering CrTiAlN hard coating and Graphite like carbon (GLC) solid lubricant coatings were applied on either one or both of the contact surfaces on tribo-partners. Ball crater device and scanning electron microscope were used to investigate surface wear of rubbed track on disc and wear scar on ball. The sliding performances of tribo-partners were evaluated in terms of coefficient of friction at sliding surfaces and specific wear rate (SWR) on both of the rubbed surfaces under specific test conditions. All test results showed that GLC solid lubricant coating on both surfaces of tappet-disc and cam-ball was the best option to allow this tribo-partners having high performance in terms of sliding under high load with low coefficient of friction and low SWR. The advantage of using GLC solid lubricant coating is to enable mechanical parts made of ordinary and sustainable materials (e.g. cast iron or plain steels) to be operated under even harsher conditions of higher load and higher wear environment with improved performance.
\end{abstract}

\section{Keywords}

Sliding, Wear, Tribo-Partners, Graphite, Lubricant, Coating

\section{Introduction}

Chilled cast iron materials have been recognized with combined properties of surface hardness and body ductility [1] [2] [3] [4] [5] and considered as one of the most common materials used to make automotive engine components, such 
as cams, tappets, gears, piston rings and cylinder liners. These components are facing increased challenges of working under severe conditions of high power, high speed, high pressure and high load in order to achieve high efficiency, down size and low emissions. Whilst surface friction wear becomes a problem that results in early failure due to loss of initial accuracy, and then power efficiency is down accompanied by increasing of fuel consumption and emissions. It was estimated [6] that more than $30 \%$ of the engine power was used to overcome friction for passenger cars, trucks and buses. Therefore, coatings with low coefficient of friction on surfaces of engine parts would be the potential technologies to upgrade traditional automotive industries.

Hard coatings, such as CrTiAlN [7] [8] [9], were widely used on cutting and forming tools for many years because of their high hardness, good adhesion and exceptional wear resistance. Whether or not the hard coatings are good for mechanical tribo-partners should be based on wide range of practical experiments and specific operational environment.

There were number of technologies reported [10] [11] [12] to produce low coefficient of friction and wear resistant coatings that improved the performance of automotive parts (such as cam-tappet, piston rings-cylinder linear, valve trains and fuel injection pumps, etc.) made of inexpensive and sustainable materials (e.g. low carbon steel, cast iron, bearing steel and stainless steels, etc.).

Carbon based, e.g. polycrystalline diamond, diamond like carbon (DLC) and amorphous graphite like carbon (GLC) coatings [13] [14] [15] [16] were reported as some of the most suitable choices used for reduction of friction coefficient and wear on tribology sliding partners. Carbon material was reported [17] to have passive film which was little interacted to its opposing surface and therefore resulted in low coefficient of friction. Stick-slip was explained as the predominant mechanism for atomic-scale friction process [18] in which high load could prompt to form tribo-layer that dramatically reduced the coefficient of friction in a sliding process. Pressure, temperature and friction of a cyclic sliding system (friction polymers, DLC coatings, varnish and metal on metal) resulted in graphitization to form tribo-film with function of solid lubricants [19].

Magnetron sputtering carbon coating was reported to have high hardness and low coefficient of friction [16] and so it could slid against opposite surfaces with very low SWR under very high load bearing capacity.

Carbon surface was recognized [20] easy to adsorb gases that saturated its surface forces leading to low attractive forces between crystallites which would contribute to low friction. It was also reported [21] that sliding on carbon surface with high stress resulted in reorientation of those carbon nano-crystallites at the top part with their (0002) planes parallel to the sliding direction. These reoriented planes provided lower shear force to its opposing surface that contributed to lower coefficient of friction.

This paper presents evaluation of sliding performances of using CrTiAlN hard 
coating and GLC solid lubricant coating on chilled cast iron tappet-disc and cam-ball tribo-partners under identical testing conditions. Comparison of testing results was made to provide an optimum system of coating to tribo-partners from which the best sliding performance was achieved.

\section{Experimental}

\subsection{Sample Preparation}

All test samples were made to form as ball against disc tribo-partners. Discs of $\emptyset 30 \times 3 \mathrm{~mm}$ were cut from chilled cast iron tappets (normally used for heavy truck). The surface of disc used for the test was the same surface on tappet to contact camshaft. Ball heads ( $\varnothing 5 \mathrm{~mm}$ cylinder in $20 \mathrm{~mm}$ length with one end machined as half ball surface with $\emptyset 5 \mathrm{~mm}$ ) were cut from chilled cast iron cams in which the half ball surface was the same surface on cam to contact tappets. Hardness of chilled cast iron was about HRC 43 in average and roughness of machined surface on disc and ball was about $0.13 \mu \mathrm{m}$ in $\mathrm{Ra}$ as measured by a roughness measuring device (SJ.400 Mitutoyo, Japan Manufacture) with average error of $0.02 \mu \mathrm{m}$.

\subsection{Coating Process}

CrTiAlN hard coatings and GLC solid lubricant coatings were deposited on surfaces of those prepared discs and ball heads using unbalanced magnetron sputtering technology with deposition method described elsewhere [22].

The deposition procedure of CrTiAlN hard coating was started with ion cleaning of using high bias potential $(-500 \mathrm{~V})$ on substrate and low power $(50$ W) on all 4 magnetrons in an Ar pressure of $3.0 \times 10^{-3}$ Torr. Then a deposition of $\mathrm{Cr}$ bond layer was conducted of using low bias potential $(-80 \mathrm{~V})$ on substrate and high power $(5.0 \mathrm{~kW})$ on 2 magnetrons of $\mathrm{Cr}$ targets. Afterwards, $\mathrm{N}_{2}$ was introduced to deposit $\mathrm{CrN}$ hard coating and quantity of $\mathrm{N}_{2}$ was feedback controlled by an optical emission monitor (OEM) set at $50 \%$ of Cr optical emission intensity. And then the powers of other 2 magnetrons ( $\mathrm{Ti}$ and $\mathrm{Al}$ targets) were increased from $50 \mathrm{~W}$ to $6.0 \mathrm{~kW}$ to deposit CrTiAlN multilayer hard coating.

The initial procedure of GLC coating was the same as that of CrTiAlN process but in which targets of $\mathrm{Ti}$ and $\mathrm{Al}$ were replaced by $\mathrm{C}$ (graphite) targets. After deposition of $\mathrm{Cr}$ bonding layer, 2 magnetron powers of $\mathrm{C}$ targets were increased from $50 \mathrm{~W}$ to $4.0 \mathrm{~kW}$ whilst magnetron power of $\mathrm{Cr}$ targets were reduced from $5.0 \mathrm{~kW}$ to $50 \mathrm{~W}$ to deposit GLC coating in Ar pressure of $3.0 \times 10^{-3}$ Torr without using reactive gases.

The process temperature for CrTiAlN coating was about $300^{\circ} \mathrm{C}$ and the temperature for GLC coating was about $200^{\circ} \mathrm{C}$ as indicated from a thermal couple in the vacuum coating chamber during deposition process.

The total coating thickness of both CrTiAlN hard coating and GLC solid lubricant coating was $3.0 \mu \mathrm{m}$. CrTiAlN coating was formed as nano-scale multilayer with poly-crystallite of $\mathrm{CrN}$ based microstructure in which each individual 
single layer was identified with a thickness of about $6 \mathrm{~nm}$ [7]. The coating composition of CrTiAlN was around atomic ratio of $30 \%, 10 \%$, and $50 \%$ for $\mathrm{Cr}, \mathrm{Ti}$, $\mathrm{Al}$ and $\mathrm{N}$ respectively. GLC solid lubricant coating was formed mainly as amorphous carbon matrix containing of graphite nano-crystallised clusters with their (0002) planes roughly vertical to the coating surface as reported by [21] using the similar coating technology. The surface roughness of CrTiAlN and GLC coated discs was $0.13 \mu \mathrm{m}$ and $0.10 \mu \mathrm{m}$ respectively with an average error of 0.02 $\mu \mathrm{m}$.

The adhesion of coatings was characterized using a Rockwell-C indentation $(150 \mathrm{~kg}$ ) and a standard diamond tip Scratch (up to a load of $60 \mathrm{~N}$ ) tests on the coated surface as reported by [23] in which the description of adhesion criteria was also used for the tests carried out in this paper. In general, all the tested coatings were characterized by good adhesion with criteria of RC $\sim 1$ and LC > $60 \mathrm{~N}$.

\subsection{Evaluation Methods}

Ball on disc wear test device [24] was used to test sliding wear of those prepared tribo-partners. The ball head was stationary under a specific load and vertically pressed on disc surface whilst the disc was rotating at a constant speed. Standard test parameters were: sliding speed, $100 \mathrm{~mm} / \mathrm{s}$; track diameter, $12 \mathrm{~mm}$; testing time, 1 hour; and load, $20 \mathrm{~N}$ for all prepared tribo-partners. High load up to 60 $\mathrm{N}$ was also used to evaluate sliding performances of tribo-partners coated by GLC solid lubricant film. Friction force or shear force was automatically recorded during the tests. All tests were operated in an air-conditional laboratory at a room temperature of $22^{\circ} \mathrm{C}$ with humidity of $35 \%$ in average.

A ball $(\varnothing 30 \mathrm{~mm})$ crater device [25] was used to make a crater section at the wear track on rubbed disc from which the track width and dimensions of the section were measured using an optical microscope as shown in Figure 1 from which coating thickness and wear depth were presented according to the measurements.

The specific wear rate (SWR) of tested disc was calculated from measured dimensions of wear track combined with testing parameters as expressed by SWR $=($ Wear Volume $) /\left(\right.$ Load ${ }^{*}$ Sliding Distance $)$ in which:

$$
\text { Wear Volume }=[(w * t) / 2] * \pi * d
$$

$w$ and $t$ present wear track width and coating wear depth respectively whilst $d$ is the diameter of wear track set up in test, $\pi * d$ is the Circumference of wear track that multiples $(w * t) / 2$ (approximate section area of wear track) to get Wear Volume.

Sliding distance $=$ Circumference ${ }^{*}$ Number of Revolutions in which Number of revolutions is set up in test. So that the SWR of coating can be written as Formula (1):

$$
\text { SWR of coating }=(\mathrm{w} * \mathrm{t}) /(\text { Load } * 2 * \text { Number of Revolutions })
$$




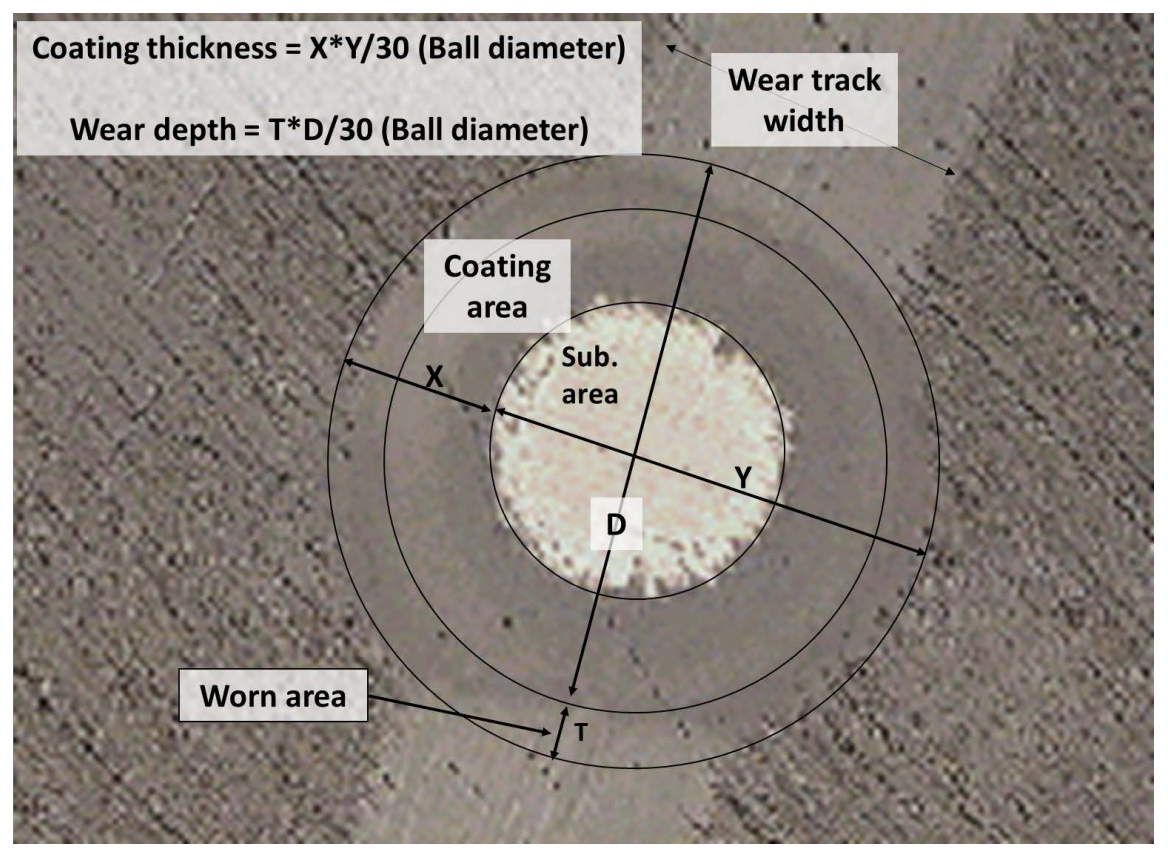

Figure 1. Schematic diagram to measure coating thickness and wear depth.

Formula (1) is based on the test situation in which wear depth is less than that of coating thickness. If the coating is completely worn off during the test, then SWR is a combined wear of both coating and substrate. In general, SWR of coating is very much less than that of chilled cast iron substrate, and therefore, SWR is normally treated as substrate wear if the coating is prematurely worn off during test.

The SWR of ball head is expressed by Formula (2).

$$
\text { SWR of ball head }=(\text { Cap Volume }) /(\text { Load } \times \text { Sliding Distance })
$$

In which Sliding Distance is $\pi^{\star} d^{\star}$ Number of Revolutions, Cap volume $(C V)$ is the worn off volume on the rubbed ball head and can be written as Formula (3).

$$
C V=(2 / 3) \pi R^{3}\left\{1-\sqrt{\left[1-\left(d^{\prime} / 2 R\right)^{2}\right]}\right\}-(1 / 3) \pi\left(d^{\prime} / 2\right)^{2}\left\{\sqrt{\left[R^{2}-\left(d^{\prime} / 2\right)^{2}\right]}\right\}
$$

In which $d^{\prime}$ is diameter of the wear scar on ball and $R$ is the radius of the ball head.

A scanning electron microscope (SEM) was used to analyse surface morphology of those rubbed tracks on discs and wear scars on ball heads. Surface composition of the rubbed track and wear scar was analysed by energy dispersive X-Ray (EDX) provided in the SEM. The energy of electron beam was adjusted by voltages in SEM so that penetration depth of electrons into surface materials to make X-ray emission would be modified by energy level of those penetrated electrons. Therefore coating composition could be selected from surface materials rather than that from body substrate. The coating had a thickness of about 3.0 micrometres whilst X-ray emission region was able adjusted at about 2 micrometres in depth. In the case of some coating was worn off, e.g. left about 1.0 
micrometre on body surface, then the composition as measured by EDX was contributed from both coating and substrate materials.

\section{Results and Discussions}

\subsection{Specific Wear Rates (SWR) of Tested Surfaces for All Tested Samples}

SWR, test parameters and measured data are shown in Table 1 to give an overview of sliding performances of tribo-partners under specific conditions.

In general, all surfaces of coated parts appeared to show significant reduction of wear comparing to uncoated parts. But GLC solid lubricant coating outperformed CrTiAlN hard coating in terms of whole system performance improvement of the tribo-partners, e.g. tribo-partners sliding with very low coefficient of friction and retaining with very low SWR on both contacted surfaces.

\subsection{Wear Mechanism of Tribo-Partners (Testing under $20 \mathrm{~N}$ Load)}

\subsubsection{Tribo-Partners without Coating}

Both disc and ball counterpart surfaces were encountered extensive wear. The wear depth of rubbed track on disc was about $12.0 \mu \mathrm{m}$ which was combined to track width and test parameters to give the highest SWR $\left(380.5 \times 10^{-16} \mathrm{~m}^{3} / \mathrm{N} \cdot \mathrm{m}\right)$ among all the tests. The wear scar on ball was a flat section with diameter of about $1366.0 \mu \mathrm{m}$ to correspond a high ball head SWR of $97.4 \times 10^{-16} \mathrm{~m}^{3} / \mathrm{N} \cdot \mathrm{m}$.

Table 1. Test parameters and SWR of tribo-partners.

\begin{tabular}{|c|c|c|c|c|c|c|c|c|}
\hline \multicolumn{9}{|c|}{$\begin{array}{l}\text { Test parameters: disc diameter } 30 \mathrm{~mm} \text {, ball head diameter } 5 \mathrm{~mm} \text {, } \\
\text { sliding speed } 100 \mathrm{~mm} / \mathrm{s} \text {, track diameter } 12 \mathrm{~mm} \text {, time } 60 \mathrm{~min} \text {, load as indicated }\end{array}$} \\
\hline \multicolumn{2}{|c|}{ Option of Tribo-partners } & \multirow{2}{*}{$\begin{array}{c}\text { Test } \\
\text { Load } \\
(\mathrm{N})\end{array}$} & \multicolumn{4}{|c|}{ Measurement data } & \multicolumn{2}{|c|}{$\begin{array}{c}\text { SWR } \\
\left(\times 10^{-16} \mathrm{~m}^{3} / \mathrm{N} \cdot \mathrm{m}\right)\end{array}$} \\
\hline $\begin{array}{l}\text { Chilled } \\
\text { cast iron } \\
\text { tappet disc }\end{array}$ & $\begin{array}{c}\text { Chilled cast } \\
\text { iron cam } \\
\text { ball head }\end{array}$ & & $\begin{array}{c}\text { Coefficient } \\
\text { of friction } \\
\text { (1) }\end{array}$ & $\begin{array}{l}\text { Wear } \\
\text { track } \\
\text { width } \\
(\mu \mathrm{m})\end{array}$ & $\begin{array}{c}\text { Wear } \\
\text { track } \\
\text { depth } \\
(\mu \mathrm{m})\end{array}$ & $\begin{array}{c}\text { Ball } \\
\text { wear } \\
\text { scar } \\
\varnothing(\mu \mathrm{m})\end{array}$ & Disc & Ball \\
\hline No coating & No coating & 20 & $0.60-0.90$ & 1220.0 & 11.9 & 1366.0 & 380.5 & 97.4 \\
\hline CrTiAlN & No coating & 20 & 0.40 & 1300.0 & $<0.1$ & 1375.0 & 3.4 & 100.0 \\
\hline No coating & CrTiAlN & 20 & $0.40-0.80$ & 914.0 & 5.8 & 1000.0 & 138.9 & 27.6 \\
\hline CrTiAlN & CrTiAlN & 20 & $0.20-0.50$ & 400.0 & $<0.1$ & 885.7 & 1.0 & 17.0 \\
\hline GLC & No coating & 20 & 0.04 & 1000.0 & $<0.1$ & 1150.0 & 2.6 & 48.6 \\
\hline No coating & GLC & 20 & 0.07 & 400 & 2.1 & 659.0 & 22.0 & 5.2 \\
\hline GLC & GLC & 20 & $0.04-0.06$ & 100 & $<0.1$ & 500.0 & 0.3 & 1.7 \\
\hline GLC none & No coating & 60 & $0.05-0.06$ & 600 & $<0.1$ & 1000.0 & 0.5 & 9.2 \\
\hline No coating & GLC & 60 & $0.18-0.75$ & 1500.0 & 5.7 & 1600.0 & 74.7 & 61.7 \\
\hline GLC & GLC & 60 & $0.02-0.06$ & 625 & $<0.1$ & 620.0 & 0.6 & 1.4 \\
\hline
\end{tabular}


The high wear on both contacted surfaces was correlated to high coefficient of frictions (0.6 to 0.9$)$ in cyclical sliding in which strong interaction was taken places among wear debris and sliding contact interfaces [26].

Figure 2 and Table 2 are given to show surface morphology of rubbed track on disc and wear scar on ball together with EDX composition profiles at pointed areas. The surface of rubbed track was rough with deep grooves. Wear debris appeared to be as abrasive particles and some of them were embedded on rubbed track. The wear scar on ball looked as rough surface morphology to indicate possibility of interlock with opposite sliding surface to contribute high coefficient of friction. These observed rough sliding surfaces gave suggestions that those upland areas would be under high stress, and become fatigued due to repeated rubbing and formed as flake-like fragments corresponded to wear [27]. EDX composition analysis of those embedded particles (point 1) and upland areas (point 2) indicated chilled cast iron based materials with very high oxygen content. It is clear that sliding over those asperities would induce high friction (or shear) force and resulted in temperature rising to correlate oxidation at rubbed interfaces [28] [29].
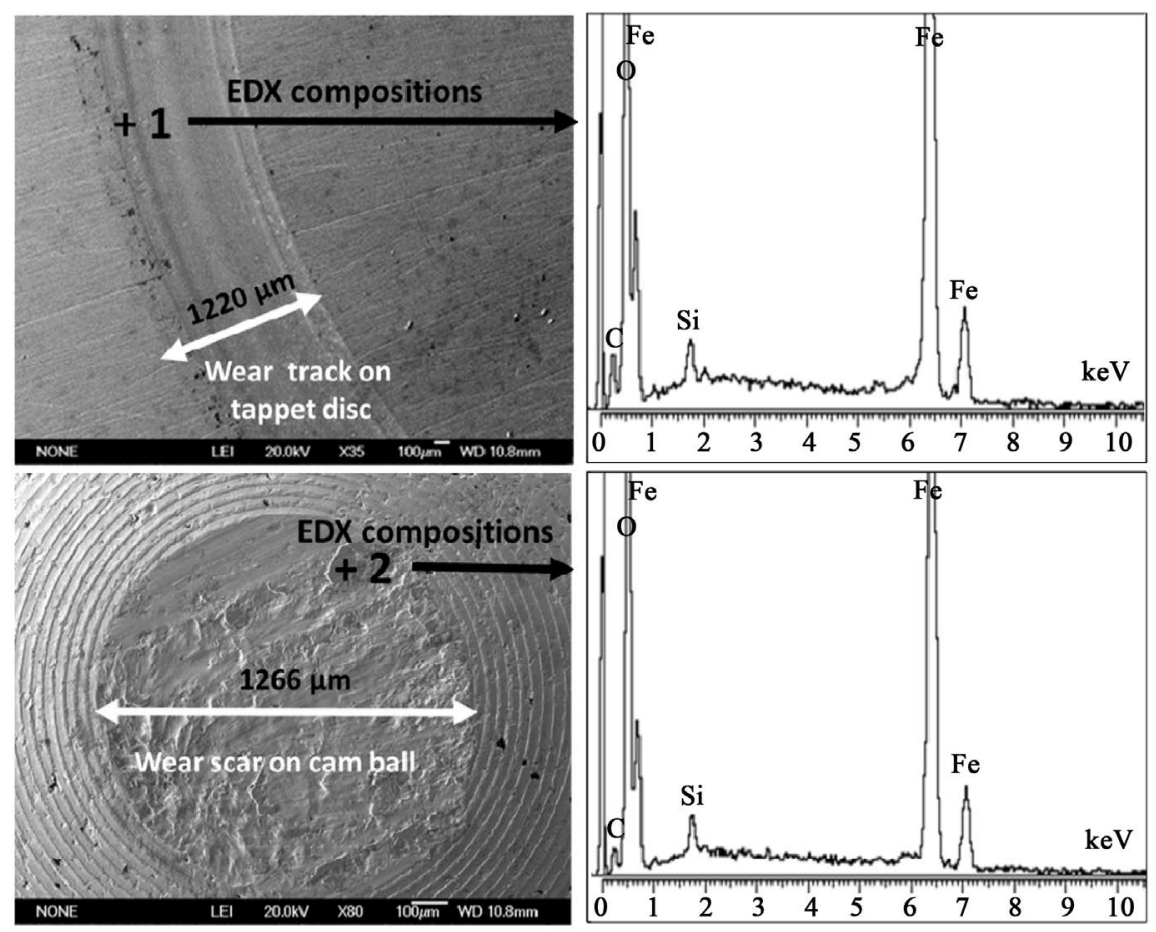

Figure 2. Surface morphology of rubbed track on disc, wear scar on ball and EDX composition profiles at pointed areas of tribo-partners without coating.

Table 2. EDX compositions at pointed areas in Figure 2.

\begin{tabular}{ccccc}
\hline Item (A\%) & $\mathrm{Fe}$ & $\mathrm{Si}$ & $\mathrm{O}$ & $\mathrm{C}$ \\
\hline P 1 & 25.2 & 1.0 & 54.6 & 19.3 \\
P 2 & 28.6 & 1.4 & 54.8 & 15.2 \\
\hline
\end{tabular}




\subsubsection{Tribo-Partners with CrTiAlN Hard Coating on Disc}

SWR of coated disc was significantly reduced for the case of tribo-partners with CrTiAlN hard coating on disc as comparing to the case of without coating. The wear depth of rubbed coating surface was hardly to measure, but $0.1 \mu \mathrm{m}$ was given as an estimation and based on this assumption, SWR of CrTiAlN coated disc was $<3.4 \times 10^{-16} \mathrm{~m}^{3} / \mathrm{N} \cdot \mathrm{m}$, about 100 times less than the case of without coating.

The coefficient of friction was moderate high at about 0.4 and CrTiAlN coating was able to tolerate this friction for one hour at almost no wear to indicate its exceptional wear resistance. Similar work was previously reported [30] [31] to explain that high hardness of CrTiAlN combined with high toughness, high bonding strength, and high thermal stability were responsible for this high wear resistance.

The ball head counterpart was, however, encountered very high wear. The wear scar was about $1400 \mu \mathrm{m}$ in diameter with a flat section that corresponded to a SWR of $100.0 \times 10^{-16} \mathrm{~m}^{3} / \mathrm{N} \cdot \mathrm{m}$, the highest ball wear among all tests. The ball was not coated and its hardness (about $500 \mathrm{HV}$ ) was much lower than that ( $>3000 \mathrm{HV}$ ) of its opposite CrTiAlN coated disc. In addition those ball wear debris were abrasive that reacted to sliding interface at ball counterpart to cause both abrasive and adhesive wear. Therefore, huge wear was taken place on the ball head surface leading to sliding performance down of the tribo-partners although CrTiAlN coated disc was not encountered much wear.

Figure 3 is given to show SEM surface morphology of rubbed track on CrTiAlN coated disc and wear scar on ball. There was not yet formed a full conformal contact surface on the rubbed track of CrTiAlN coated disc after one hour

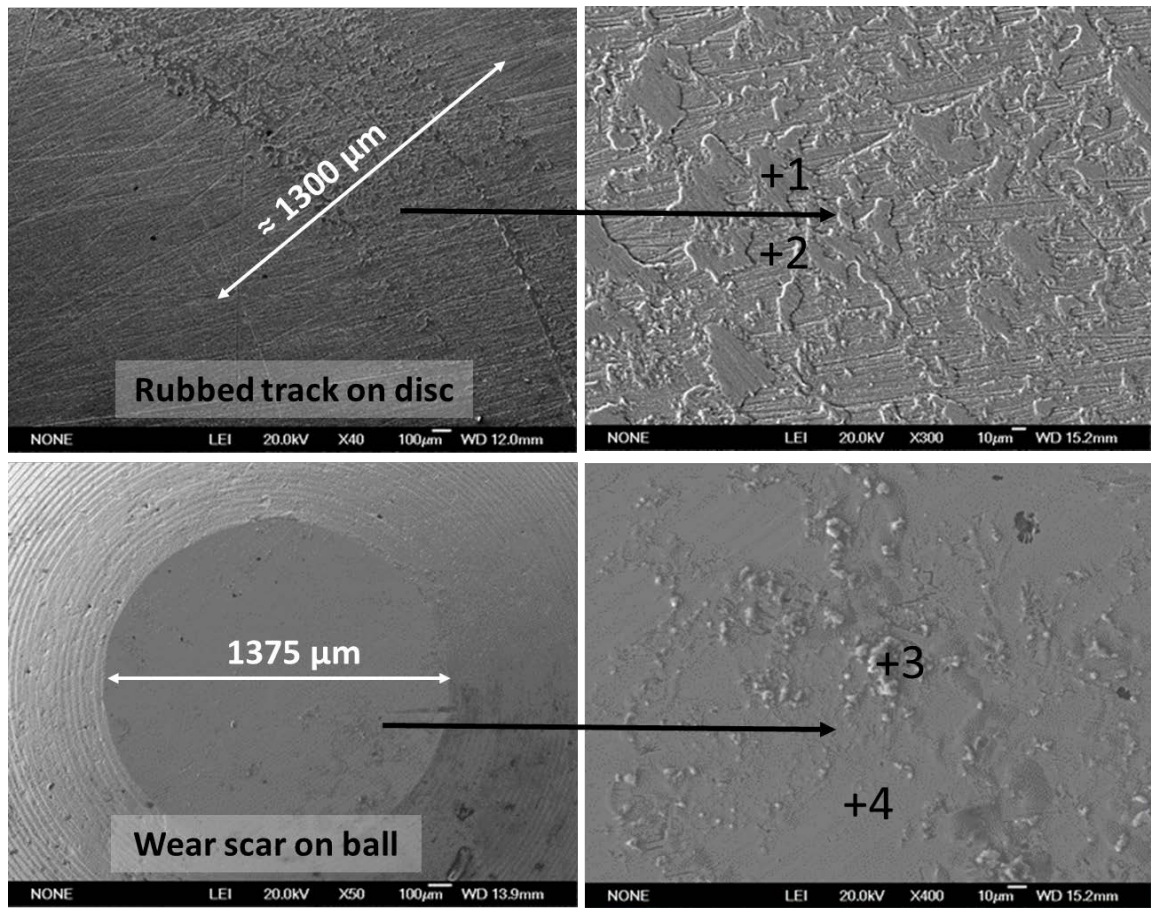

Figure 3. Surface morphology of rubbed track on disc and wear scar on ball of tribopartners with CrTiAlN coated disc. 
sliding test although its opposite ball head was encountered extensive wear. Ball wear debris were accommodated on the rubbed coating surface to form network plateaus. Therefore, sliding interfaces were mainly chilled cast iron against chilled cast iron with little involving of the underneath coating. There should be very high stress transferred to the local coating surface during sliding but the underneath coating surface was able to support sliding interface with no plastic deformation, cracking, delamination and noticeable wear to indicate high resistance to stress induced fatigue, abrasive and adhesive wear.

EDX compositions at pointed areas in Figure 3 are given in Table 3. Those upland areas (point 1 in Figure 3) on rubbed coating surface were formed by $\mathrm{Fe}$ based materials whilst materials at pool bottom area (point 2 in Figure 3) were based as CrTiAlN coating. Wear debris of flaks up to $10 \mu \mathrm{m}$ in diameter were found on the ball counterpart (point 3) and composition were identified as $\mathrm{Fe}$ based materials. High oxygen was found at sliding interfaces especially at those true contacted (or highland) areas to indicate rubbing induced oxidation due to temperature rising.

\subsubsection{Tribo-Partners with CrTiAlN Hard Coating on Ball Head}

SWR of rubbed track on disc was $138.9 \times 10^{-16} \mathrm{~m}^{3} / \mathrm{N} \cdot \mathrm{m}$ and SWR of CrTiAlN coated ball head was $27.6 \times 10^{-16} \mathrm{~m}^{3} / \mathrm{N} \cdot \mathrm{m}$. The wear reduction of CrTiAlN coated ball head was not as sufficient as that of CrTiAlN coated disc. This was because the coted ball head surface was in "point" contact to sliding disc and continuously encountered high stress and high shear force. Coating at this area was, therefore, undergoing cracking, fracturing and spalling failures. And then, the coating on ball head counterpart surface was completely worn off resulted in sliding interfaces as chilled cast iron against chilled cast iron with high coefficient of friction and high SWR.

Table 3. EDX composition analysis of sliding interfaces on tribo-partners with CrTiAlN coating.

\begin{tabular}{cccccccccc}
\hline Types & Point & $\mathrm{Fe}$ & $\mathrm{Cr}$ & $\mathrm{Ti}$ & $\mathrm{Al}$ & $\mathrm{Si}$ & $\mathrm{O}$ & $\mathrm{N}$ & $\mathrm{C}$ \\
\hline & 1 & 16.7 & 15.5 & 1.8 & 0.0 & 0.0 & 56.3 & 0.0 & 9.7 \\
CrTiAlN & 2 & 1.5 & 33.6 & 3.1 & 5.7 & 0.0 & 18.1 & 38.0 & 0.0 \\
on disc Figure 3 & 3 & 14.5 & 0.0 & 0.0 & 0.0 & 0.0 & 43.8 & 0.0 & 41.7 \\
& 4 & 64.8 & 0.0 & 0.0 & 0.0 & 2.3 & 0.0 & 0.0 & 32.9 \\
& 1 & 58.5 & 0.0 & 0.0 & 0.0 & 2.0 & 0.0 & 0.0 & 39.5 \\
CrTiAlN & 2 & 24.8 & 0.0 & 0.0 & 0.0 & 2.0 & 48.9 & 0.0 & 24.3 \\
on ball Figure 4 & 3 & 25.9 & 0.0 & 0.0 & 0.0 & 1.0 & 58.0 & 0.0 & 15.1 \\
& 4 & 59.1 & 0.0 & 0.0 & 0.0 & 0.0 & 0.0 & 0.0 & 40.9 \\
& 1 & 0.0 & 34.9 & 3.4 & 6.2 & 0.0 & 14.1 & 41.4 & 0.0 \\
brTiAlN on & 2 & 0.6 & 36.3 & 3.2 & 4.9 & 0.0 & 5.9 & 49.1 & 0.0 \\
both disc \& ball Figure 5 & 3 & 42.8 & 8.1 & 2.2 & 1.4 & 0.8 & 0.0 & 44.7 & 0.0 \\
& 4 & 79.2 & 2.2 & 0.0 & 0.0 & 2.0 & 0.0 & 0.0 & 16.6 \\
\hline
\end{tabular}


Figure 4 is given to show rubbed track on disc and wear scar on CrTiAlN coated ball. The wear phenomenon was similar to that of steel sliding against steel with stress induced plastic deformation, fatigue, abrasive and adhesive wear [27] [28] [29]. The rubbed track appeared to be rough with deep grooves and small flaks scattered on the surface. Some small protruded areas with flat top are shown in Figure 4 at point 2 and point 3 with dark grey colour that were identified as chilled cast iron with high oxygen as shown in Table 3 . Therefore, coating on the ball head counterpart surface was completely removed and rubbing induced oxidation was taking places to indicate temperature rising at sliding interfaces.

\subsubsection{Tribo-Partners with CrTiAlN Hard Coating on Both Disc and Ball Head}

SWR of rubbed track on coated disc was about $<1.0 \times 10^{-16} \mathrm{~m}^{3} / \mathrm{N} \cdot \mathrm{m}$ based on an estimation of wear depth of $0.1 \mu \mathrm{m}$ and this SWR was 380 times less than the case of tested disc without coating. SWR of wear scar on coated ball was evaluated at $17.0 \times 10^{-16} \mathrm{~m}^{3} / \mathrm{N} \cdot \mathrm{m}$, about 6 times lower than the case of ball head wear without coating.

Figure 5 is given to present surface morphology of rubbed track on disc and wear scar on ball whilst EDX compositions at pointed areas are given in Table 3.

There was little wear taken places at rubbed coating surface on disc as the surface morphology was almost the same as its original surface. There was very little adhered wear debris on rubbed track of CrTiAlN coated disc to indicate wear debris from coated ball were less adhesive comparing to Fe based wear debris.
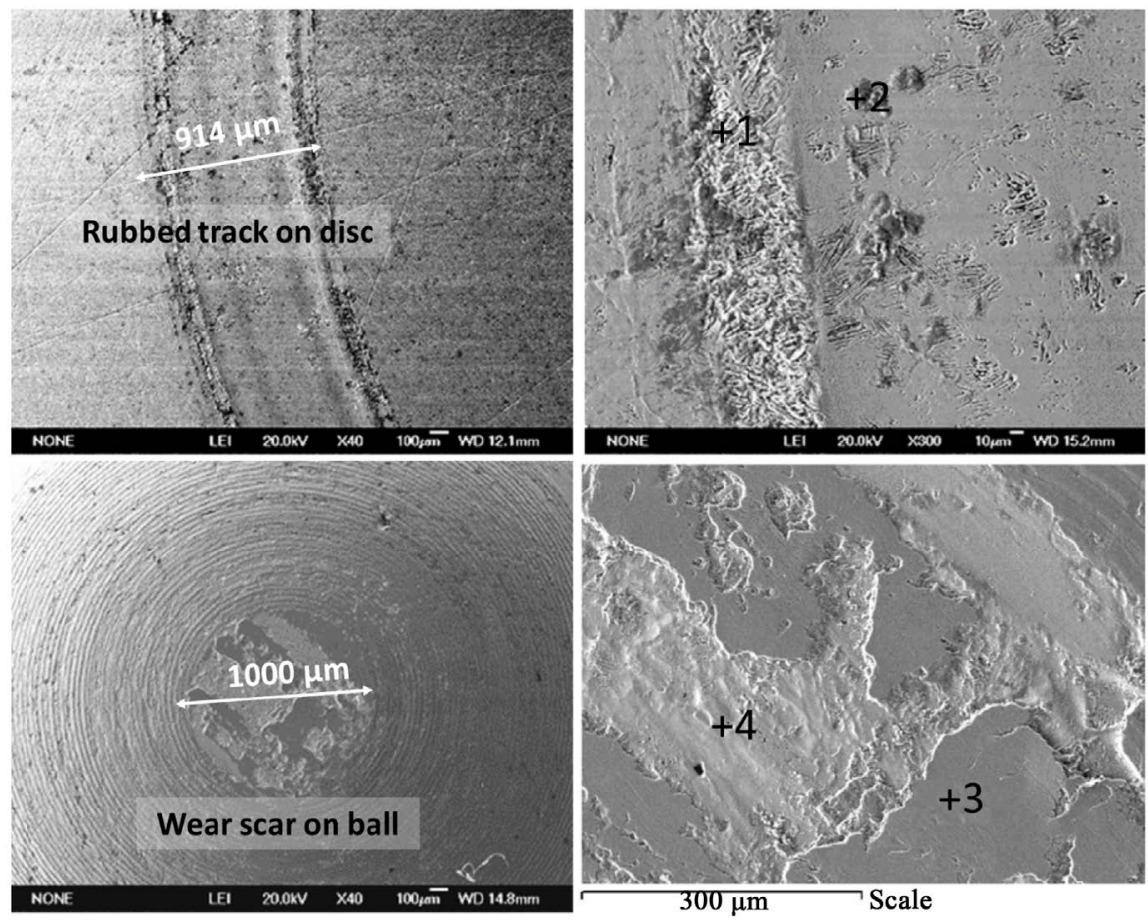

Figure 4. Surface morphologies of rubbed track on disc and wear scar on ball of tribopartners with CrTiAlN coated ball. 


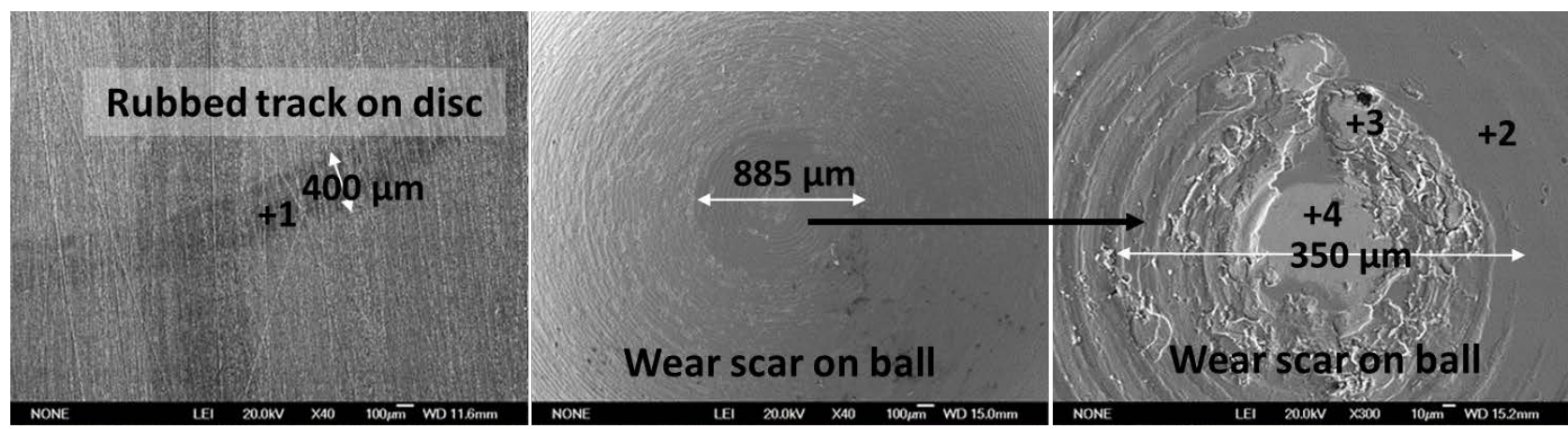

Figure 5. Surface morphology of rubbed track on disc and wear scar on ball of tribo-partners with CrTiAlN coated both disc and ball.

The diameter of wear scar on coated ball was about 2 times larger than the width of rubbed track on coated disc. It was because wear debris of coated ball head counterpart were accommodated along areas close to both edges of the rubbed track on coated disc. When the ball ran over of those abrasive wear debris, rubbing scar was formed on the ball due to continuously being crashed and pressed by abrasive debris whilst the track on disc was only periodically under sliding. In addition the surface of coated disc was very hard with ability to resist abrasive. Therefore wear scar on ball became larger due to more progress surface wear. The actual wear area on ball was up to about $350 \mu \mathrm{m}$ in diameter as shown in Figure 5 where the central surface of around $120 \mu \mathrm{m}$ in diameter was flat and smooth to indicate micro-abrasive wear. EDX composition analysis at the centre area (point 4 in Figure 5) was identified as Fe based material to indicate coating at this area was almost worn off. Outside of this area, the rubbed surface appeared to show stress induced chipping and flaking failures on the coating surface. The size of those chips and flaks was about $10 \mu \mathrm{m}$ in diameter. EDX composition analysis (Table 3) at those chipped and flaked areas (point 3 in Figure 5) showed coating to be still existence to imply that coating failures were taken places at top surface with no further propagating down to the substrate indicating of coating with high bonding strength to substrate [30].

A Hertz contact stress $\left[3 f\left(2 \times \pi \times r^{2}\right)\right.$, in which $\mathrm{f}$ and $\mathrm{r}$ presents normal load and radius of the wear scar respectively, and $\mathrm{r}$ was also assumed as the "true" radius of contact area on the ball] was estimated of about $312 \mathrm{MPa}$. This stress is about the level of yielding stress ( $\approx 400 \mathrm{MPa})$ for chilled cast iron raw materials. Although the ball was still under protection of the exist CrTiAlN coating, there was tendency that the coating on ball head counterpart surface would be soon worn off and then it could be expected to have extensive wear on the ball leading to sliding performance down of tribo-partners as discussed in 3.2.2.

\subsubsection{Tribo-Partners with GLC Solid Lubricant Coating on Disc}

Both SWR and coefficient of friction of the tribo-partners were very low when disc was coated by GLC solid lubricant film. The coefficient of friction was about 0.04 to 0.06 throughout testing and wear depth on disc was impossible to meas- 
ure. Surface morphologies of rubbed track on GLC coated disc and wear scar on ball are shown in Figure 6 and EDX compositions at pointed areas are given in Table 4.

The rubbed track on disc was about $1000 \mu \mathrm{m}$ in width with no measurable wear depth as the rubbed surface retained its original morphology. But $0.1 \mu \mathrm{m}$ was given as estimation of wear depth to specify a SWR $<2.6 \times 10^{-16} \mathrm{~m}^{3} / \mathrm{N} \cdot \mathrm{m}$ for the rubbed track of coated disc, about 150 times less than case of without any coatings.

There were some small wear debris accommodated at those tiny-valleys on rubbed coating surface (point 1 in Figure 6) identified as $\mathrm{Fe}, \mathrm{Cr}, \mathrm{O}$ and $\mathrm{C}$ materials as presented in Table 4. Sliding over oxide metal particles in contact with graphite [19] would lead to graphitization of those particles becoming as lubricants to correspond to low coefficient of friction.

The wear scar on ball was flat and smooth with a diameter of $1150 \mu \mathrm{m}$ that corresponded to a SWR of $48.6 \times 10^{-16} \mathrm{~m}^{3} / \mathrm{N} \cdot \mathrm{m}$, about two times lower than the case of without any coating. This low SWR was due to very low coefficient of
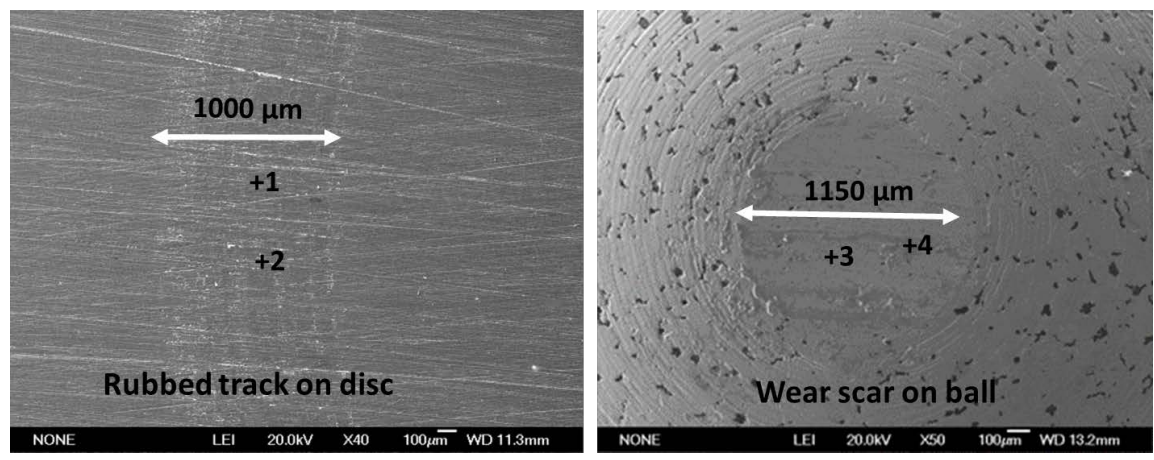

Figure 6. SEM surface morphology of rubbed track on disc and wear scar on ball of tribo-partners with GLC coated disc.

Table 4. EDX composition analysis of sliding interfaces on tribo-partners with GLC coating.

\begin{tabular}{ccccccc}
\hline Types & Point & $\mathrm{Fe}$ & $\mathrm{Cr}$ & $\mathrm{Si}$ & $\mathrm{O}$ & $\mathrm{C}$ \\
\hline \multirow{3}{*}{ GLC on disc Figure 6 } & 1 & 4.3 & 12.7 & 0.0 & 15.3 & 67.7 \\
& 2 & 1.0 & 13.3 & 0.0 & 0.0 & 85.7 \\
& 3 & 97.2 & 0.0 & 2.8 & 0.0 & 0.0 \\
& 4 & 28.8 & 0.9 & 0.8 & 53.6 & 15.9 \\
GLC on ball Figure 7 & 1 & 68.1 & 0.6 & 1.6 & 0.0 & 29.7 \\
& 2 & 34.4 & 1.1 & 1.9 & 62.6 & 0.0 \\
& 3 & 0.4 & 10.2 & 0.0 & 3.8 & 85.6 \\
GLC on both disc \& ball Figure 8 & 4 & 42.4 & 4.2 & 1.1 & 0.0 & 52.3 \\
& 1 & 0.7 & 11.1 & 0.0 & 0.0 & 88.2 \\
& 2 & 1.2 & 11.9 & 0.0 & 0.0 & 86.9 \\
& 3 & 15.9 & 18.3 & 0.0 & 6.8 & 59.0 \\
\hline
\end{tabular}


friction at sliding interface provided by its opposite GLC coated partner. Low coefficient of friction was responsible to low shear force and therefore the sliding wear was reduced accordingly.

High carbon was identified at some specific areas on ball counterpart, e.g. point 4 with dark grey colour in Figure 6. This indicated rubbing induced transfer of $\mathrm{C}$ materials which were formed as stick-slip areas on counterpart surface [18] and would contribute to low coefficient of friction. In addition $\mathrm{O}$ was found at contact surfaces to indicate rubbing induced oxidation due to temperature rising at the sliding interfaces.

\subsubsection{Tribo-Partners with GLC Solid Lubricant Coating on Ball Head}

The coefficient of friction during sliding was as low as about 0.06 to 0.07 throughout the testing. SWR of rubbed discs was $<22.0 \times 10^{-16} \mathrm{~m}^{3} / \mathrm{N} \cdot \mathrm{m}$ based on estimation of a wear track width of $400 \mu \mathrm{m}$. SWR of the GLC coated ball was estimated of $<5.2 \times 10^{-16} \mathrm{~m}^{3} / \mathrm{N} \cdot \mathrm{m}$ according to assumption of a flat wear section with diameter of $659 \mu \mathrm{m}$. The SWR of both rubbed disc and GLC coated ball was around at least 20 times less than the case of without any coating.

Figure 7 is given to show the surface morphologies of rubbed track on disc and wear scar on GLC coated ball together with EDX composition on pointed areas as given in Table 4 .

The rubbed track on disc was about $400 \mu \mathrm{m}$ in width but main surface area in this track remained almost the same as its original morphology and both track edges were hardly to distinguish. There was a groove with width and depth about $100 \mu \mathrm{m}$ and $2.1 \mu \mathrm{m}$ respectively at the track centre to indicate the possible wear caused by this test. EDX analysis inside the groove (point 1 and 2 in Figure 7) specified compositions of $\mathrm{Fe}, \mathrm{Cr}, \mathrm{Si}, \mathrm{O}$ and $\mathrm{C}$ based elements to indicate carbon was transferred due to rubbing and oxidation was identified as a result from rubbing induced temperature rising.

It can be seen from Figure 7 that those original machined surface morphology (about $0.13 \mu \mathrm{m}$ in roughness) on ball head counterpart was not yet worn off. The wear scar on ball counterpart appeared as a polished curved surface rather than a flat worn off sections as shown in Figures 2-4 and Figure 6 in this paper. This
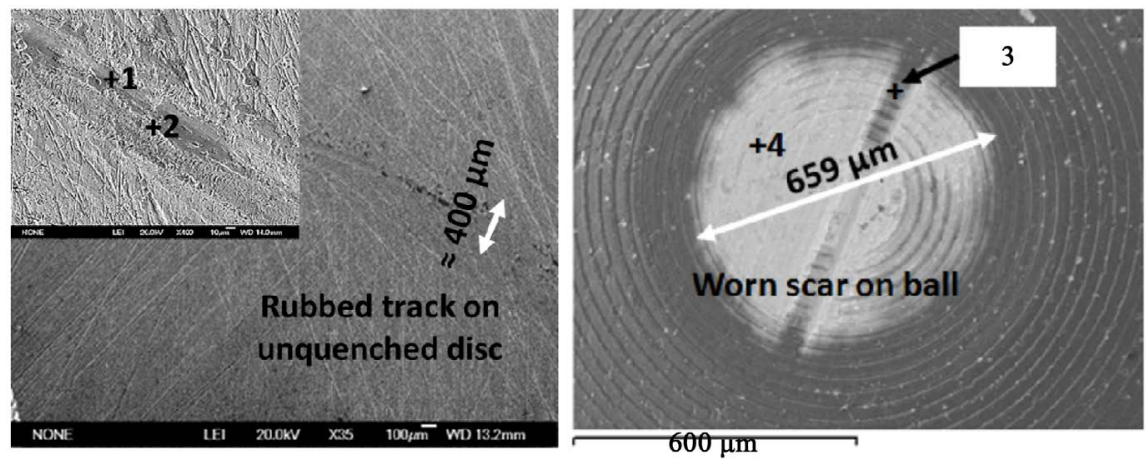

Figure 7. Surface morphologies of rubbed track on disc and wear scar on ball of tribopartners with GLC coated ball. 
indicated that the sliding interface was well supported by GLC solid lubricant coating and not much wear was taken place from the ball head surface. EDX analysis of the ball counterpart surface showed carbon based material to classify that GLC coating was still covering the rubbed scar. The surface was smooth with no sign of coating fractures on the contacted area implying that the shear force at sliding interfaces was not high enough to cause cracking, chipping and flaking at the rubbed surface on GLC coated ball head.

\subsubsection{Tribo-Partners with GLC Solid Lubricant Coating on Both Disc and Ball Head}

The coefficient of friction was as low as 0.04 to 0.06 throughout the testing. SWR of GLC coated disc and ball was estimated of about $<0.3 \times 10^{-16} \mathrm{~m}^{3} / \mathrm{N} \cdot \mathrm{m}$ and $<1.7 \times 10^{-16} \mathrm{~m}^{3} / \mathrm{N} \cdot \mathrm{m}$ respectively based on assumption of $0.1 \mu \mathrm{m}$ wear depth on rubbed disc and flat section of $500 \mu \mathrm{m}$ diameter on ball head counterpart. Both SWR on rubbed disc and ball head counterpart surfaces were the lowest among all the specific tests. Comparing to the cases of CrTiAlN coated and without any coating, GLC solid lubricant coating was the choice to promote sliding performance of tribo-partner system in terms of low coefficient of friction and low SWR on both sliding interfaces and GLC solid lubricant coating on both surfaces of the tribo-partners was the best option for an optimized sliding performances of the ball to disc tribo-partners.

Figure 8 is given to show the surface morphology of rubbed track on GLC coated disc and wear scar on GLC coated ball together with EDX composition at pointed areas as given in Table 4 . The rubbed track on disc appeared almost as its original morphology to indicate very little wear. There was a rubbed scar on ball with about $500 \mu \mathrm{m}$ in diameter but only about $1 / 3$ of the scar area (in white grey colour) was possibly in true contact with its opposing surface.

If the white grey area in Figure 8 was assumed as the true contact surface, a contact stress was estimated of about $450 \mathrm{MPa}$ on this area. This contact stress was higher than yielding stress of chilled cast iron raw materials. The GLC coated tribo-partners were, however, able to tolerate this stress sliding for one hour with very little wear on both surfaces to indicate the exceptional advantages of
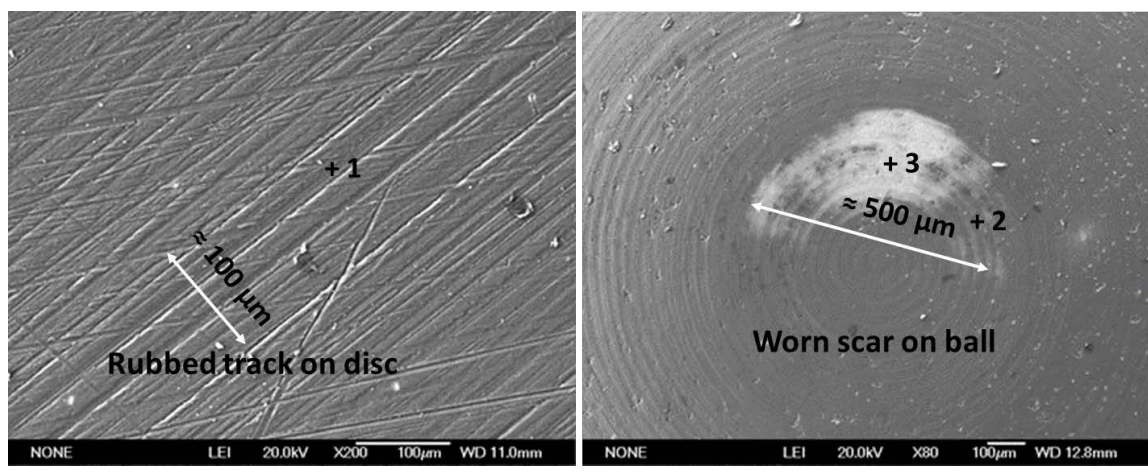

Figure 8. Surface morphology of rubbed track on disc and wear scar on ball of tribopartners with GLC coated both disc and ball. 
GLC coating, e.g. coated components with ability to operate at very high load bearing capacity.

EDX compositions on rubbed surfaces were shown in Table 4 to indicate the rubbed surfaces were consisted of coating based materials with $\mathrm{O}$ (due to rubbing induced oxidation) and $\mathrm{Fe}$ (contributed from underneath substrate). The level of $\mathrm{O}$ at sliding interfaces was much lower than that of cases without coating or with CrTiAlN coating. This indicated that low coefficient of friction at sliding interfaces could moderate rubbing induced temperature rising due to less thermal energy dispensed at rubbed surfaces and accordingly with less oxidation.

\subsection{Wear Mechanism of Tribo-Partners (Testing under $60 \mathrm{~N}$ Load)}

$60 \mathrm{~N}$ high load was used to evaluate the sliding performance of GLC coated chilled cast iron tappet disc and cam ball Tribo-partners. The tribo-partners with CrTiAlN hard coating or without any coating were unable to endure this testing because that high normal stress and high shear force resulted in high wear at rubbed surfaces. Then the sliding interface was prematurely failed leading to the test was stopped due to high vibration.

\subsubsection{Tribo-Partners with GLC Coating on Disc (Testing under $60 \mathrm{~N}$ Load)}

The coefficient of friction was still very low, about 0.05 to 0.06 throughout the testing although with a high load of $60 \mathrm{~N}$. SWR of the rubbed track on GLC coated disc and wear scar on ball was about $0.5 \times 10^{-16} \mathrm{~m}^{3} / \mathrm{N} \cdot \mathrm{m}$ and $9.2 \times 10^{-16}$ $\mathrm{m}^{3} / \mathrm{N} \cdot \mathrm{m}$ respectively. It was clear that low friction force or low shear force at sliding interfaces was the direct fact to enable this tribo-partners enduring sliding under high load with very low SWR. The maximum shear force during this test was about $60 \times 0.06=3.6 \mathrm{~N}$, much lower than that $(20 \times 0.5=10.0 \mathrm{~N})$ of cases under $20 \mathrm{~N}$ load with either CrTiAlN coating or without coating. Therefore, low coefficient of friction at the sliding interfaces can moderate the severe level when load was high, and so the tribo-partners were still able to provide good sliding performance.

\subsubsection{Tribo-Partners with GLC Coating on Ball Head (Testing under $60 \mathrm{~N}$ Load)}

The coefficient of friction was started from low (about 0.16) but it was increased gradually up to about 0.8 close to the end of test. SWR of rubbed disc and GLC coated ball head counterpart were about $74.7 \times 10^{-16} \mathrm{~m}^{3} / \mathrm{N} \cdot \mathrm{m}$ and $61.7 \times 10^{-16}$ $\mathrm{m}^{3} / \mathrm{N} \cdot \mathrm{m}$ respectively. This high SWR was due to GLC coating on ball head counterpart surface was gradually and completely worn off during test. The wear on rubbed track of uncoated disc was first taken places and then those wear debris (chilled cast iron based materials) were abrasive to the sliding interfaces resulting in accelerated wear on GLC coated ball head counterpart surface. As soon as GLC coating on the ball head counterpart surface was completely worn off, the sliding interfaces became as chilled cast iron against chilled cast iron with high SWR. 


\subsubsection{Tribo-Partners with GLC Coating on Both Disc and Ball Head (Testing under $60 \mathrm{~N}$ Load)}

The coefficient of friction was about 0.03 to 0.07 throughout the testing. SWR of rubbed track on GLC coated disc was less than $0.6 \times 10^{-16} \mathrm{~m} / \mathrm{N} \cdot \mathrm{m}$ and SWR of wear scar on GLC coated ball head was less than $1.4 \times 10^{-16} \mathrm{~m}^{3} / \mathrm{N} \cdot \mathrm{m}$. SWR of both the disc and ball was based on assumption of $0.1 \mu \mathrm{m}$ wear depth on rubbed disc and flat wear section on ball head counterpart. It was evidenced again that GLC coating on both disc and ball head provided the best option for this tribopartners to give optimum sliding performance under high load.

Surface morphologies of rubbed track on GLC coated disc and wear scar on GLC coated ball head are given in Figure 9 together with EDX composition at pointed areas as shown in Table 5. The rubbed track on GLC coated disc had a width of about $625 \mu \mathrm{m}$ with unmeasurable wear depth because that the coating original morphology was clear to see. There were two areas on rubbed track as shown in point 1 and 2 respectively. EDX compositions at these areas indicated as carbon based coating materials. Fe was also identified to indicate small wear from the ball head counterpart centre area according to the following discussions.

Fe content at point 2 area was much higher than that at point 1 . This was because for some reason (e.g. ball head slightly tilted under high load) that the inner track area was more truly in contact with ball counterpart surface and therefore more wear debris were accommodated at this area to responsible higher $\mathrm{Fe}$ content. Interesting thing was that no sign of abrasive wear identified on the rubbed surface. This was due to the carbon content was also high in this area
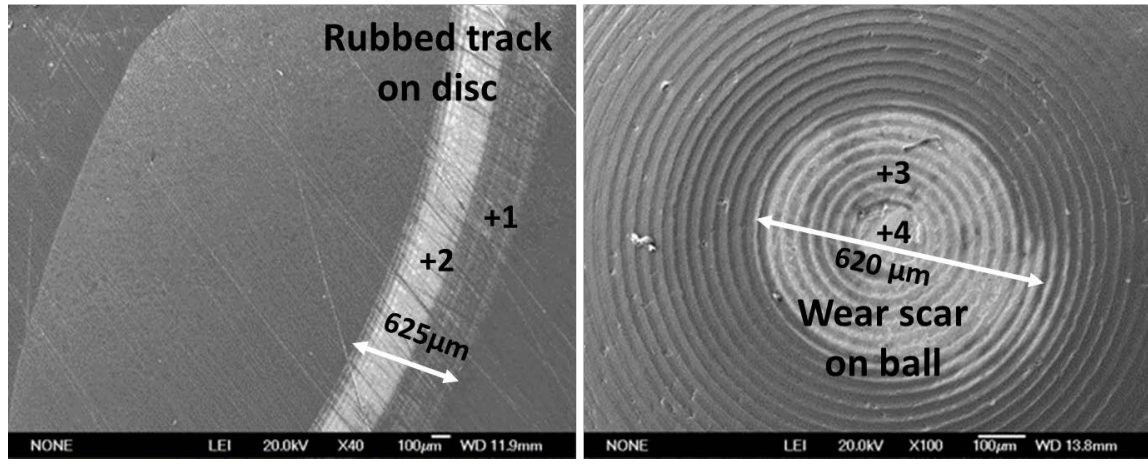

Figure 9. Surface morphology of rubbed track on disc and wear scar on ball of tribopartners w GLC coated both disc and ball (test under load of $60 \mathrm{~N}$ ).

Table 5. EDX compositions at pointed areas in Figure 9.

\begin{tabular}{cccccc}
\hline Items & $\mathrm{Fe}$ & $\mathrm{Cr}$ & $\mathrm{Si}$ & $\mathrm{O}$ & $\mathrm{C}$ \\
\hline P 1 & 5.5 & 15.5 & $\approx 0$ & $\approx 0$ & 79.0 \\
P 2 & 60.4 & $\approx 0$ & 1.6 & $\approx 0$ & 38.0 \\
P 3 & 5.8 & 12.6 & $\approx 0$ & $\approx 0$ & 81.6 \\
P 4 & 65.0 & $\approx 0$ & $\approx 0$ & $\approx 0$ & 35.0 \\
\hline
\end{tabular}


and so rubbing induced graphitization was taken place with function as more slippery rather than abrasive. It was reported [32] that GLC coating against iron based metals (GCr15) exhibited low coefficient of friction and low specific wear rate due to low adhesion between contact surfaces and formation of carbon lubricant transfer materials. In addition, the sliding interfaces were mainly GLC coated surfaces and therefore all of these factors would allow tribo-partners to form easy shearing interfaces with very low coefficient of friction and very low SWR under very high load bearing capacity.

The wear scar on ball counterpart as shown in Figure 9 was not as a flat wear section but appeared as polished circular curved surface with about $620 \mu \mathrm{m}$ in diameter. This is very much similar to surface morphology as shown in Figure 7 and Figure 8 in this paper. There was only a small area at the centre, about 100 $\mu \mathrm{m}$ in diameter, appeared to be flat to indicate the possible ball wear at this area. EDX composition analysis (point 4 in Figure 9) did indicate Fe based materials with about $35 \%$ at carbo, implying that iron and high carbon mixture under rubbing conditions would be formed as lubricants to maintain low coefficient of friction.

Thus enough evidences were given that GLC coating on both surfaces of the tribo-partners provided benefit of very low friction coefficient to the sliding interfaces. The tribo-partner system was, therefore, able to operate under very high load with very low specific wear rate.

\section{Conclusions}

- Sliding performance of chilled cast iron disc/ball tribo-partners was systematically evaluated in terms of coefficient of friction, specific wear rate and load bearing capacities at sliding interfaces.

- The tribo-partners without coating were conducted high coefficient of friction at sliding interfaces that incorporated to stress on the counterpart surfaces to correspond high abrasive and adhesive wear.

- CrTiAlN hard coating gave protection to coated surface with exceptional wear resistance. But high coefficient of friction and stress at sliding interface were responsible to the opposite surface with high wear and so degraded the tribo-partners' sliding performances.

- GLC solid lubricant coating on either surface of tappet-disc or cam-ball provided very low coefficient of friction or very low shear force at sliding interfaces. This lubricant property gave moderation of harsh conditions at sliding interfaces leading to tribo-partners with exceptional sliding performances.

- The best option is to apply GLC solid lubricant coating on both surfaces of the tribo-partners, so the system can be operating with very low coefficient of friction and very low specific wear rate under ever higher load bearing capacity.

\section{References}

[1] Muzzamil Ahamed, S., Kumar, Y.V., Rahman, J.F. and Bharat, V. (2014) Mechani- 
cal Properties of Sub Zero Chilled Cast Iron Useful for Wear Functional Requirements of Engineering Components. Procedia Materials Science, 5, 540-549. https://doi.org/10.1016/j.mspro.2014.07.298

[2] Michalski, J., Marszalek, J. and Kubiak, K. (2000) An Experimental Study of Diesel Engine Cam and Follower Wear with Particular Reference to the Properties of the Materials. Wear, 240, 168-179. https://doi.org/10.1016/S0043-1648(00)00353-7

[3] Mallikarjuna, V., Jashuva, N., Nagaraju, G. and Rama Bhupal Reddy, B. (2014) Design Manufacturing and Cost Estimation of Camshaft Used in two Wheeler. Journal of Mechanical and Civil Engineering, 11, 53-67. https://doi.org/10.9790/1684-11145367

[4] Yogesha, K.B. and Hemanth, J. (2012) Mechanical Properties of Metallic and NonMetallic Chilled Austempered Ductile Iron. International Journal of Advanced Engineering Research and Studies, I, 240-243.

[5] Olawale, J.O., Ibitoye, S.A. and Oluwasegun, K.M. (2016) Processing Techniques and Productions of Ductile Iron: A Review. International Journal of Scientific \& Engineering Research, 7, 397-423.

[6] Holmberg, K. and Erdemir, A. (2015) Global Impact of Friction on Energy Consumption, Economy and Environment. FME Transactions, 43, 181-185.

[7] Yang, S.C., Li, X. and Teer, D.G. (2002) The Properties and Performance of CrTiAlN Multilayer Hard Coatings Deposited Using Magnetron Sputter Ion Platin Surface. Engineering, 18, 391-396. https://doi.org/10.1179/026708402225006295

[8] Yang, S.C., Wiemann, E. and Teer, D.G. (2004) The Properties and Performance of Cr-Based Multilayer Nitride Hard Coatings Using Unbalanced Magnetron Sputtering and Elemental Metal Targets. Surface \& Coatings Technology, 188-189, 662 668. https://doi.org/10.1016/j.surfcoat.2004.07.032

[9] Lu, L., Wang, Q.-M., Chen, B.-Z., Ao, Y.-C., Yu, D.-H., Wang, C.-Y., Wu, S.-H. and Kim, K.H. (2014) Microstructure and Cutting Performance of CrTiAlN Coating for High-Speed Dry Milling. Transactions of Nonferrous Metals Society of China, 24, 1800-1806. https://doi.org/10.1016/S1003-6326(14)63256-8

[10] Louda, P. (2007) Applications of Thin Coatings in Automotive Industry. Journal of Achievements in Materials and Manufacturing Engineering, 24, 51-55.

[11] Malani, A.S., Chaudhari, A.D. and Sambhe, R.U. (2016) A Review on Applications of Nanotechnology in Automotive Industry. International Journal of Mechanical, Aerospace, Industrial, Mechatronic and Manufacturing Engineering, 10, 36-40.

[12] Patel Kalpeshkumar, P. (2014) A Review on Surface Treatment on Piston Ring and Cylinder Linear. International Journal of Engineering Development and Research, 2, 1323-1326.

[13] Hayward, I.P. (1991) Friction and Wear Properties of Diamonds and Diamond Coatings. Surface and Coatings Technology, 49, 554-559. https://doi.org/10.1016/0257-8972(91)90116-E

[14] Oguri, K. and Arai, T. (1991) Tribological Properties and Characterization of Diamond-Like Carbon Coatings with Silicon Prepared by Plasma-Assisted Chemical Vapour Deposition. Surface and Coatings Technology, 47, 710-721. https://doi.org/10.1016/0257-8972(91)90344-V

[15] Liu, Y., Erdemir, A. and Meletis (1997) Influence of Environmental Parameters on the Frictional Behaviour of DLC Coatings. Surface and Coatings Technology, 94-95, 463-468. https://doi.org/10.1016/S0257-8972(97)00450-7

[16] Yang, S., Camino, D., Jones, A.H.S. and Teer, D.G. (2000) Deposition and Tribological Behaviour of Sputtered Carbon Hard Coatings. Surface and Coatings Techno- 
logy, 124, 110-116. https://doi.org/10.1016/S0257-8972(99)00634-9

[17] Erdemir, A. and Donnet, C. (2006) Tribology of Diamond-Like Carbon Films: Recent Progress and Future Prospects. Journal of Physics D: Applied Physics, 39, R311-R327. https://doi.org/10.1088/0022-3727/39/18/R01

[18] Nian, J., Si, Y. and Guo, Z. (2016) Advances in Atomic-Scale Tribological Mechanisms of Solid Interfaces. Tribology International, 94, 1-13. https://doi.org/10.1016/j.triboint.2015.08.013

[19] Hoffman, E.E. and Marks, L.D. (2016) Graphitic Carbon Films across Systems. Tribology Letters, 63, 32. https://doi.org/10.1007/s11249-016-0720-9

[20] Midgley, J.W. and Teer, D.G. (1962) An Investigation of the Mechanism of the Friction and Wear of Carbon. Transaction of the ASME-ASLE Lubrication Conference, 16-18 October 1962, Pittsburgh, 62-Lub-15.

[21] Yanga, S., Li, X., Reneviera, N.M. and Teer, D.G. (2001) Tribological Properties and Wear Mechanism of Sputtered C/Cr Coating. Surface and Coatings Technology, 142-144, 85-93. https://doi.org/10.1016/S0257-8972(01)01147-1

[22] Kingmag Precise Sci-Tech Ltd. (2012) Unbalanced Magnetron Sputtering Coating Equipment Operation Manual.

[23] Yang, S., Jones, A.H.S. and Teer, D.G. (2000) The Development of Sputtered Carbon Based Coatings Incorporating Cr, Ti, B and N. Surface and Coatings Technology, 133-134, 369-375.

[24] Kingmag Precise Sci-Tech Ltd. (2010) Ball-on-Disc Wear Test Device, Operation Manual.

[25] Kingmag Precise Sci-Tech Ltd. (2010) Ball Crater Film Thickness Measurement Device.

[26] Perez Delgado, Y., Bonny, K., De Baets, P., Neis, P.D., Rodriguez Fereira, V., Malek, O., Vleugels, J. and Lauwers, B. (2011) Dry Sliding Friction and Wear Response of WC-Co Hardmetal Pairs in Linearly Reciprocating and Rotating. Sustainable Construction and Design, 2, 12-18.

[27] Kimura, Y. and Sugimura, J. (1984) Microgeometry of Sliding Surfaces and Wear Particles in Lubricated Contact. Wear, 100, 33-45. https://doi.org/10.1016/0043-1648(84)90004-8

[28] Sharma, G., Limaye, P.K., Ramanujan, R.V., Sundararaman, M. and Prabhu, N. (2004) Dry-Sliding Wear Studies of $\mathrm{Fe}_{3} \mathrm{Al}$-Ordered Intermetallic Alloy. Materials Science and Engineering $A, 386,408-414$. https://doi.org/10.1016/S0921-5093(04)00999-2

[29] Elhadi, A., Bouchoucha, A., Jomaa, W., Zedan, Y., Schmitt, T. and Bocher, P. (2016) Study of Surface Wear and Damage Induced by Dry Sliding of Tempered AISI 4140 Steel against Hardened AISI 1055 Steel. Tribology in Industry, 38, 475-485.

[30] Yang, S., Cooke, K.E., Li, X., McIntosh, F. and Teer, D.G. (2009) CrN-Based Wear Resistant Hard Coatings for Machining and Forming Tools. Journal of Physics D. Applied Physics, 42, Article ID: 104001 https://doi.org/10.1088/0022-3727/42/10/104001

[31] Alberdi, A., Marin, M., Diaz, B., Sanchez, O. and Escobar Galindo, R. (2007) Wear Resistance of Titanium-Aluminium-Chromium-Nitride Nanocomposite Thin Films. Vacuum, 81, 1453-1456. https://doi.org/10.1016/j.vacuum.2007.04.024

[32] Wang, Y., Wang, L., Li, J., Chen, J. and Xue, Q. (2013) Tribological Properties of Graphite-Like Carbon Coatings Coupling with Different Metals in Ambient Air and Water. Tribology International, 60, 147-155. https://doi.org/10.1016/j.triboint.2012.11.014 